\title{
Effects of Propranolol during Pregnancy and Development of Rats. I. Adverse Effects during Pregnancy
}

\author{
N. SCHOENFELD, ${ }^{(33)}$ O. EPSTEIN, L. NEMESH, M. ROSEN, AND A. ATSMON \\ Laboratory of Biochemical Pharmacology and The Animal House of the Beilinson Medical Center, Petah Tiqva and \\ The Sackler School of Medicine, Tel Aviv University, Ramat Aviv, Israel
}

\begin{abstract}
Summary
Pregnant rats, treated with high doses of propranolol, gave birth to small for dates neonates. Litter size was affected in daily doses of 100 and $150 \mathrm{mg} / \mathrm{kg} /$ day. Propranolol markedly influenced the gain in weight normally observed in pregnant rats. The placentas of the rats which received the higher doses of propranolol weighed about $30 \%$ less than normal placentas.

\section{Speculation}

Pregnant rats, treated with propranolol, gave birth to small for dates neonates. This effect is possibly the result of a drug-induced reduction in transport across cellular membranes, resulting in malnutrition. Since similar effects were reported in humans, treatment with propranolol during pregnancy should be further reevaluated in laboratory animals.
\end{abstract}

The administration of propranolol to pregnant women is slowly gaining acceptance. If the present trend continues it will possibly become one of the more extensively used drugs for a variety of conditions associated with pregnancy such as: hypertension $(2,6)$, hyperthyroidism $(1,12)$, cardiac arrhythmias $(13,16,20)$, and hypertrophic obstructive cardiomyopathy $(5,7,25)$. A relatively large number of side effects on the process of parturition and on the newborn have been reported. One of these side effects is intrauterine growth retardation $(2,6,16)$ often accompanied by a small or fibrotic placenta $(6,16)$. These findings are thought to be caused by sustained increase in uterine muscle tone or hemodynamic changes in the mother and in the fetus resulting from $\beta$ adrenoceptor blockade by propranolol (16).

In previous investigations we have shown that high concentrations of propranolol partially inhibit the uptake of amino acids $(17,18)$, uridine and thymidine (19), and 2-deoxyglucose (3) by chick embryo liver cells in vitro. Preliminary experiments indicate that the same inhibition may occur in mammalian cells, both in vitro and in vivo. This creates a situation analogous to starvation, which would exert its effects mainly on rapidly dividing cells or tissues with a high metabolic rate.

Propranolol crosses the mammalian placenta (14) and its pharmacologic effects on the fetus are easily demonstrated $(9,10)$. In view of our previous laboratory findings and the reports of small placentas and fetuses in women receiving propranolol during pregnancy, a methodical investigation on the effects of this drug in pregnant rats was initiated.

\section{MATERIALS AND METHODS}

\section{ANIMALS}

The experiments were carried out using Wistar rats, randomly bred, and weighing 140-160 g. Timed pregnant rats were obtained by mating virgin females with experienced male rats for a 24-hr period. $d l$-Propranolol was administered starting the morning after impregnation.

Oral administration of $d l$-propranolol was achieved by dissolving the drug in the water imbibed by the rats. The concentrations of propranolol in the drinking water were based upon long term measurements of the average consumption of water containing propranolol per rat per $24 \mathrm{hr}$, which was found to be about $25 \pm$ $7 \mathrm{ml} /$ day. The concentrations were such that each group of rats received approximately either $25,50,100$, or $150 \mathrm{mg} / \mathrm{kg} /$ day. During these preliminary measurements and all subsequent experiments each rat was housed in an individual, stainless steel cage, $28 \times 28 \times 14 \mathrm{~cm}$, containing soft wood shavings, room temperature $22 \pm 2^{\circ}$, and a relative humidity of $40-60 \%$.

Pregnant rats were maintained on Ambar food pellets and tap water ad libitum with or without propranolol.

\section{DETERMINATION OF PROPRANOLOL}

The concentration of propranolol in plasma, liver, and placenta was determined in a group of rats after long term oral administration of various amounts of propranolol as described above. Blood samples were obtained after decapitation. The samples were transferred to heparinized tubes and the plasma was separated. Propranolol was measured by a minor modification of the method described by Shand et al. (22). Samples, containing $0.5 \mathrm{ml}$ plasma and $1.5 \mathrm{ml}$ saline, were alkalinized with $1 \mathrm{ml} 1 \mathrm{~N} \mathrm{NaOH}$ and extracted into $12 \mathrm{ml}$ heptane containing $1.5 \%$ isoamyl alcohol. After centrifugation, $10 \mathrm{ml}$ of the organic phase was extracted into $3.0 \mathrm{ml} 0.1 \mathrm{~N} \mathrm{HCl}$ and the fluorescence of the acid phase measured in a Farrand spectrophotofluorometer (excitation $295 \mathrm{~nm}$, emission $360 \mathrm{~nm}$ ). The assay was linear up to $2000 \mathrm{ng} / \mathrm{ml}$ of known concentrations of the drug in plasma.

Livers and placentas were homogenized in 5 vol $0.1 \mathrm{~N} \mathrm{HCl}$. After centrifugation $2 \mathrm{ml}$ of the supernatant were alkalinized with $1 \mathrm{ml} 1 \mathrm{~N} \mathrm{NaOH}$ and further worked up as above. Separate standard curves were made by addition of measured amounts of propranolol to liver extracts of normal, age-matched rats.

Statistical evaluations were made using Student's $t$-test.

\section{RESULTS}

Pregnant rats, treated with high doses of propranolol, gave birth to small for dates neonates. In a dose of $50-150 \mathrm{mg} / \mathrm{kg} /$ day it reduced significantly each individual neonate's weight. Litter size was affected in daily doses of 100 and $150 \mathrm{mg} / \mathrm{kg} /$ day and the total litter weight was reduced accordingly. Propranolol 25 $\mathrm{mg} / \mathrm{kg} /$ day had no effect on the parameters studied (Table 1 ).

Propranolol markedly influenced the gain in weight normally observed in pregnant rats (Fig. 1).

The weight of control rats increased during pregnancy by $44 \%$. An increase of $31.0 \%$ and $20.5 \%$ occurred in the rats treated with 50 and $100 \mathrm{mg} / \mathrm{kg} / \mathrm{day}$ of propranolol, respectively. Those rats 
which were given $150 \mathrm{mg} / \mathrm{kg} /$ day actually had an absolute weight loss during pregnancy. The differences in weight were statistically highly significant.

The placentas of the rats which received the higher doses of propranolol were smaller than those of normal rats and weighed about 30\% less than normal placentas. With the highest dosage very small and macroscopically fibrotic placentas were observed. The embryos connected with these placentas had either been completely reabsorbed or were in the form of small lumps of tissue (Fig. 2).

Figure 2 shows a rather extreme example of the influence of $150 \mathrm{mg} / \mathrm{kg} /$ day propranolol upon the development of the fetuses. Only 2 out of 11 fetuses were partially developed, the other 9 were small pieces of flesh attached to small placentas.

The mean concentration of propranolol in the plasma, the liver and the placentas of rats at the 20th day of pregnancy and of the fetuses at the same time was determined in another group of rats. Plasma propranolol levels varied up to 20 -fold after administration of similar amounts of propranolol; the other parameters also showed marked variabilities (Fig. 3).

Figure 3 clearly indicates that the average individual neonatal weight was much more closely related to plasma levels of propranolol in the pregnant rats than to the concentration of propranolol in any one of the organs examined. It is also seen that at a dose of $100 \mathrm{mg} / \mathrm{kg} /$ day the livers and placentas were nearly completely saturated and increasing the daily dose had a small effect only on the concentration of the drug in these organs.

\section{DISCUSSION}

We have previously shown that the uptake of amino acids, thymidine, and uridine by cultures of chick embryo liver cells is partially inhibited by propranolol in a concentration range of 5 $\times 10^{-5}-2 \times 10^{-4} \mathrm{M}(17-19)$. Further experiments showed that the uptake of deoxyglucose is similarly inhibited (3). This partial inhibition of uptake may be equated to a state of cellular starvation in spite of an adequate milieu. In the present study the oral administration of propranolol to rats throughout pregnancy led to reduced neonatal weight and litter size. It is difficult to compare the conditions in a well defined tissue culture medium to the situation prevailing in vivo in the pregnant rat. Moreover, the concentration of propranolol in the plasma of the rats was lower than that used in the culture media by 2 orders of magnitude. However, initial results of another series of experiments with pregnant rats show inhibition of uptake of amino acids by the liver cells of the fetuses on days 18-20 using dosages of propranolol as described in this paper. Thus, the low weight of the newborn litters might indicate partial starvation of the rat fetuses in utero.

Table 1. Litter size and weight of neonates of rats treated with dlpropranolol during pregnancy ${ }^{1}$

\begin{tabular}{cccc}
\hline $\begin{array}{c}\text { Pro- } \\
\text { pran- } \\
\text { olol, } \\
\mathrm{mg} /\end{array}$ & & & \\
$\mathrm{kg} /$ day & Litter size & $\begin{array}{c}\text { Total wt of } \\
\text { neonates/litter, } \mathrm{g}\end{array}$ & $\begin{array}{c}\text { Individual } w t \\
\text { of neonates, } \mathrm{g}\end{array}$ \\
\hline 0 & $10.5 \pm 2.1$ & $56.4 \pm 10.9$ & $5.36 \pm 0.44$ \\
25 & $10.1 \pm 1.5$ & $52.9 \pm 9.9$ & $5.40 \pm 0.59$ \\
& $\mathrm{NS}$ & $\mathrm{NS}$ & $\mathrm{NS}$ \\
50 & $9.3 \pm 1.5$ & $46.6 \pm 8.3$ & $4.99 \pm 0.40$ \\
& $0.1<P<0.2$ & $0.05<P<0.100$ & $P<0.001$ \\
100 & $8.2 \pm 1.5$ & $39.1 \pm 7.9$ & $4.76 \pm 0.39$ \\
& $0.01<P<0.025$ & $P<0.001$ & $P<0.001$ \\
150 & $6.0 \pm 2.5$ & $24.2 \pm 10.9$ & $4.22 \pm 0.49$ \\
& $P<0.001$ & $P<0.001$ & $P<0.001$ \\
\hline
\end{tabular}

${ }^{1}$ The values are means \pm SD of determinations in $30-136$ neonates in 5-13 litters in each group. NS: non-significant.

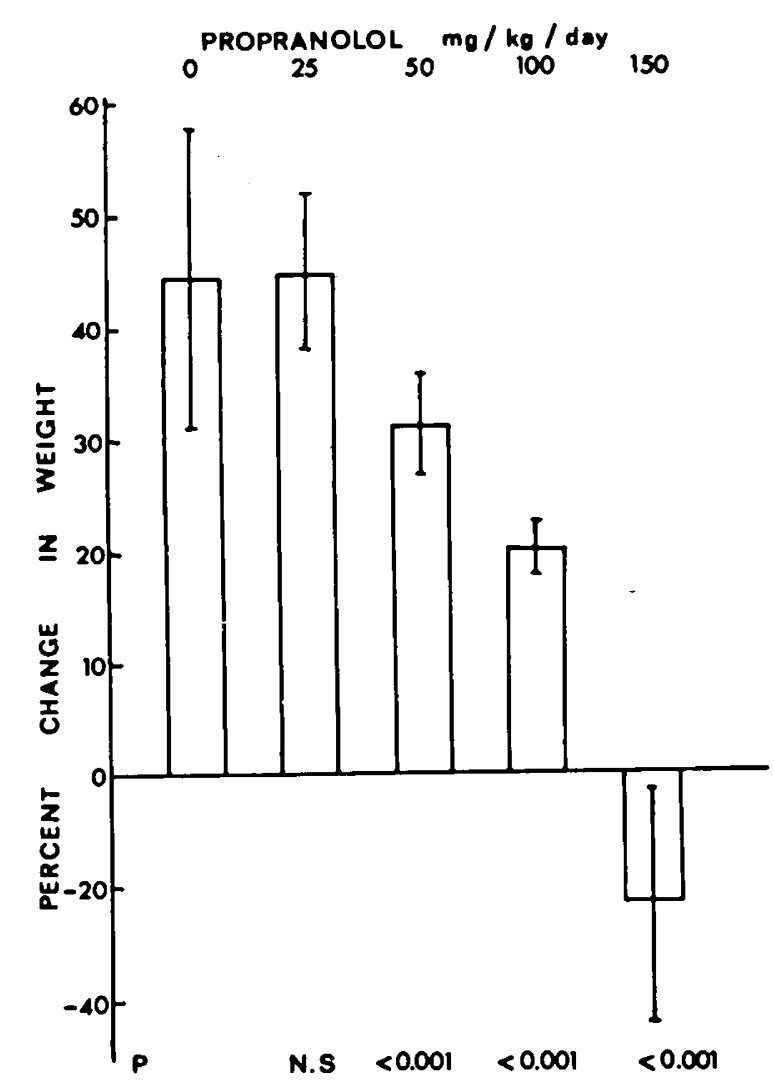

Fig. 1. Percentage change in weight of mothers during pregnancy. Weights of mothers within a few hours after parturition as compared to their weights on the first day of pregnancy. Results are expressed as means \pm SD in 5-11 rats in each group. Note the difference in scale, above and below the zero line.

The small size of the placenta observed in these rats is in accordance with this concept.

The disposition of propranolol has proven to be highly complicated and its pharmacokinetics are dependent on the route and duration of administration. In humans 20 -fold variations in plasma levels may follow single, similar, orally administered doses, both in adults (21) and in children (27). The wide variations are apparently caused by differences in the rate of absorption from the gut. During chronic oral administration of propranolol plasma concentrations are at least twice as high as after single dose administration and the half-life of the drug is prolonged (4). The pharmacokinetics of propranolol in the rat resembles those in humans $(8,23)$.

Because of the marked individual differences in the pharmacokinetics of orally administered propranolol, it is advantageous to compare plasma levels instead of oral dosages. It is not certain whether similar plasma levels of propranolol in rats and in humans have similar effects, even without taking into account the lack of data on active metabolites. Nevertheless, such a comparison will be made, mainly because of its ominous implications.

Plasma levels of $160 \pm 100 \mathrm{ng} / \mathrm{ml}$ propranolol, measured at the 20 th day of pregnancy, caused the neonates to be of lower weight than controls. At higher plasma levels, average 360 and $764 \mathrm{ng} / \mathrm{ml}$, a significant decrease in both the litter size and in neonatal weight was observed. The smaller litter size was probably caused by death and reabsorption of some of the embryos or fetuses. Thus the deleterious effects observed were proportional to both the daily dosage and to the concentration of propranolol in the plasma.

The plasma levels observed in the pregnant rats receiving up to $100 \mathrm{mg} / \mathrm{kg}$ propranolol daily have also been described in humans who were receiving dosages of propranolol ranging from 80-160 $\mathrm{mg} /$ day $(11,22)$. There are no data indicating that similar, high plasma levels of propranolol in rats and in humans have comparable effects. Nevertheless, our observations indicate that sponta- 


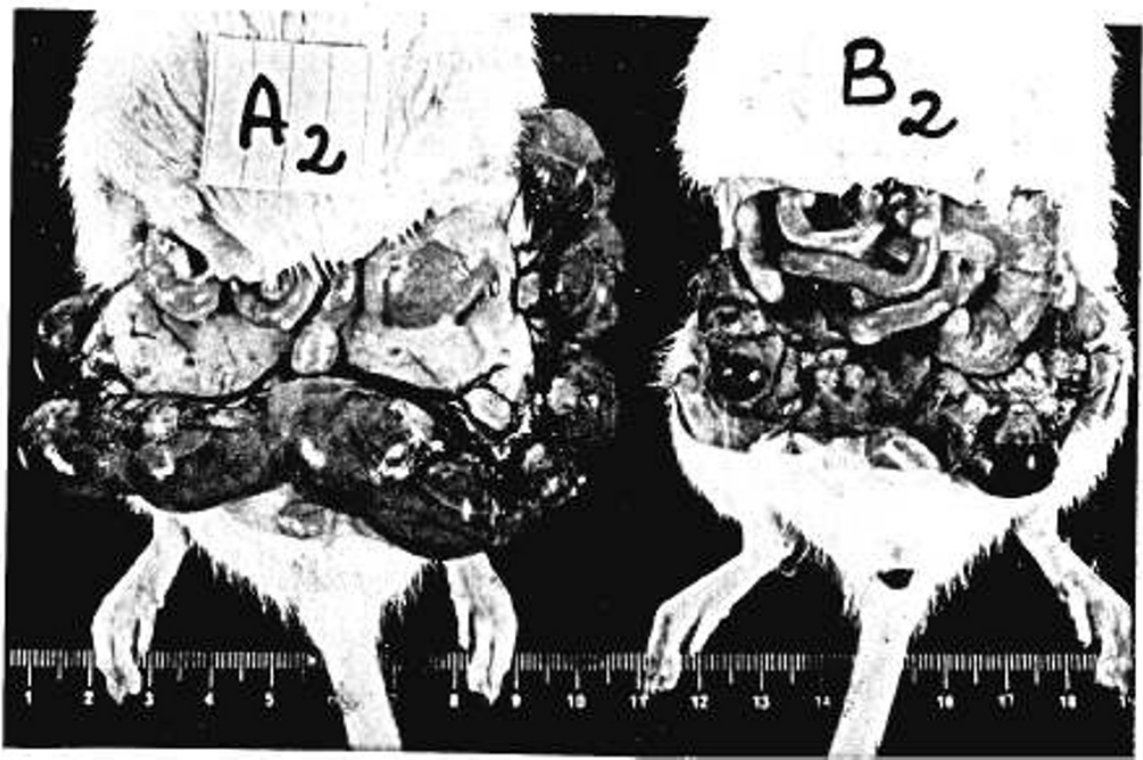
Fig. 2. Uteri of rats on the 18 th day of pregnancy. $A_{2}$ is a control rat; $B_{2}$ is a rat to which $150 \mathrm{mg} / \mathrm{kg} /$ day of propranolol was administered orally
throughout pregnancy.

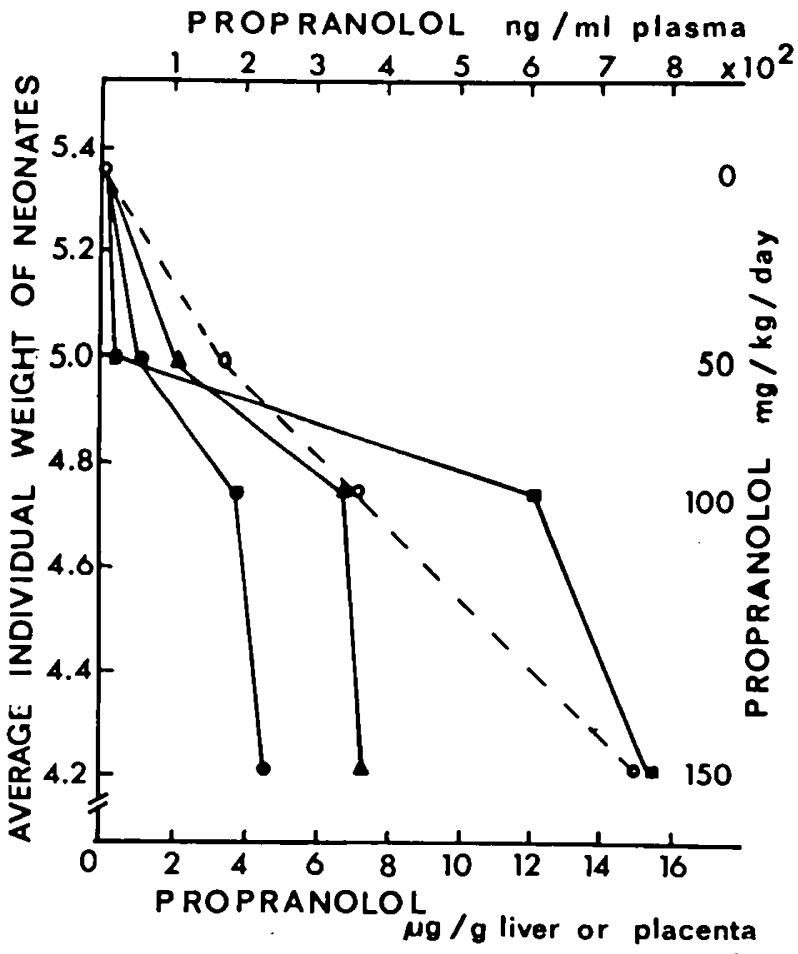

Fig. 3. Relation of average individual weight of neonates to the concentration of propranolol in the plasma, the livers and the placentas of pregnant rats and in the livers of the fetuses on the 20th day of pregnancy. Each point represents the means of values obtained in four to seven rats. O: in plasma; : in livers of pregnant rats.

neous abortions and small for dates infants occurring in pregnancies during which the mothers received propranolol up to 240 $\mathrm{mg} /$ day (6) could, in part, have been caused by this drug. However, the primary diseases for which propranolol is administered may also have a deleterious influence on the course of pregnancies.

The observations in humans have been interpreted as being caused by increased muscular tone of the uterus and hemodynamic changes and reflexes in the uterine and fetal circulation due to propranolol (16). Obviously such effects may cause small for dates infants at birth, small placentas, premature birth, and abortion.
According to the concept developed here these phenomena might be the result of inhibition of uptake of nutrients by the developing placenta and fetal cells caused by high concentrations of propranolol. This mechanism of "malnutrition" might be operative when the other effects are so mild as not to have a deleterious influence.

Malnutrition during fetal and neonatal life may cause irreversible developmental changes in general (26) and also in the brain where it may result in decreased number and size of cells in various brain areas (for review see Ref. 28), changes in the lipid composition of myelin (24) and of several enzymes $(15,24)$. The same applies, apparently, to human infants (28). These organic changes may have irreversible behavioral effects. Moreover, temporal arrest of development of the brain during certain critical periods of gestation may be revealed by symptoms of minimal brain damage at a later date, although the infant was of normal weight at term.

At present we are investigating the organic and mental development of rats and the reversibility of arrested development caused by the administration of propranolol during pregnancy and after parturition.

Our data, based upon observations in rats, cannot, at present, be interpreted as constituting an absolute contraindication for the administration of propranolol during pregnancy. Nevertheless, they call for caution when high dosages are thought to be required. Monitoring of blood levels of propranolol would seem to be indicated at all daily dosages. High blood levels should probably be avoided until more data will be available from further detailed investigations in laboratory animals.

\section{REFERENCES AND NOTES}

1. Bullock, J. L., Harris, R. E., and Young, R.: Treatment of thyrotoxicosis during pregnancy with propranolol. Amer. J. Obstet. Gynecol., 121: 242 (1975).

2. Eliahou, H. E., Silverberg, D. S., Reisin, E., Masshiach, S., and Romem, I. Propranolol in the treatment of hypertension in pregnancy. To be published.

3. Epstein, O., Wysenbeek, A., Schoenfeld, N., and Atsmon, A.: The inhibitory effect of beta-adrenoceptor blocking drugs on the uptake of $2 \cdot{ }^{-i 4} \mathrm{C}$-deoxyglucose by cultured chick embryo liver cells. To be published.

4. Evans, G. H., and Shand, D. G.: Disposition of propranolol. V. Drug accumulation and steady-state concentrations during chronic oral administration in man. Clin. Pharmacol. Ther., 14: 487 (1973).

5. Fiddler, G. L.: Propranolol and pregnancy. Lancet, 3: 722 (1974).

6. Gladstone, G. R., Hordof, A., and Gersony, W. M.: Propranolol administration during pregnancy: Effects on the fetus. J. Pediat., 86: 962 (1975).

7. Goodwin, J. F., and Oakley, C. M.: The cardiomyopathies. Brit. Heart J. 34: 545 (1972).

8. Hayes, H., and Cooper, R. G.: Studies on the absorption, distribution and excretion of propranolol in rat, dog and monkey. J. Pharmacol. Exp. Ther., 176: 302 (1971).

9. Joelson, I., and Barton, M. D.: The effect of blockade of the beta receptors of the 
sympathetic nervous system of the fetus. Acta Obstet. Gynecol., Scand., 3: 75 (1969).

10. Joelson, I., Barton, M. D., Daniel, S. et al.: The response of the unanesthetized sheep fetus to sympathomimetic amines and adrenergic blocking agents. Amer. J. Obstet. Gynecol., 114: 43 (1972).

11. Kanto, J., Kleimola, T., Mantyla, R. et al.: Pharmacological effect of propranolol after a single oral dose. Acta Pharmacol. Toxicol., 39: 573 (1976).

12. Langer, A., Hung, C. T., Mc A'Nulty, J. A., et al: Adrenergic blockade: A new approach to hyperthyroidism during pregnancy. Obstet. Gynecol., 44: 181 (1974).

13. Levitan, A. A., and Manion, M. D.: Propranolol therapy during pregnancy and lactation. Amer. J. Cardiol., 32: 247 (1973).

14. Masuoka, D., and Hansson, E.: Autoradiographic distribution studies of adrenergic blocking agents. II. ${ }^{14} \mathrm{C}$-Propranolol, a $\beta$-receptor-type blocker. Acta Pharmacol. Toxicol., 25: 447 (1967).

15. Rajalakshmi, R., Parameswaran, M., Telang, S. D. et al.: Effects of undernutrition and protein deficiency on glutamate dehydrogenase and decarboxylase in rat brain. J. Neurochem., 23: 129 (1974).

16. Reed, R. L., Cheney, C. B., Fearon, R. E., et al.: Propranolol therapy throughout pregnancy: A case report. Anesthes. Analges. Current Res., 53: 214 (1974).

17. Schoenfeld, N., and Atsmon, A.: The effect of beta-adrenergic blocking agents on incorporation of amino acids into protein in tissue cultures of chick embryo liver cells. Biochem. Pharmacol., 26: 867 (1977).

18. Schoenfeld, N., Epstein, O., and Atsmon, A.: Inhibitory effect of membrane active compounds on the uptake of ${ }^{14} \mathrm{C}$ - $\alpha$-aminoisobutyric acid (AIB) in cultured chick embryo liver cells. Life Sci., 21: 329 (1977).

19. Schoenfeld, N., Epstein, O., and Atsmon, A.: Inhibitory effect of some membrane active drugs on RNA and DNA synthesis in cultured chick embryo liver cells. Biochem. Biophys. Res. Commun., 76: 460 (1977).

20. Schroeder, J. S., and Harrison, D. C.: Repeated cardioversion during pregnancy: Treatment of refractory paroxysmal atrial tachycardia during 3 successive

Copyright ( 1978 International Pediatric Research Foundation, Inc. $0031-3998 / 78 / 1207-0747 \$ 02.00 / 0$ pregnancies. Amer. J. Cardiol., 27: 445 (1971).

21. Shand, D. G.: Pharmacokinetics of propranolol: A review. Postgrad. Med. J., 52: 22 (1976).

22. Shand, D. G., Nuckolls, E. M., and Oates, J. A.: Plasma propranolol levels in adults with observations in four children. Clin. Pharm. Ther., 11: 112 (1970).

23. Shand, D. G., Rangno, R. E., and Evans, G. H.: The disposition of propranolol. II. Hepatic elimination in the rat. Pharmacology, $8: 344$ (1972).

24. Simons, S. D., and Johnston, P. V.: Prenatal and postnatal protein restriction in the rat: Effect on some parameters related to brain development, and prospects for rehabilitation. J. Neurochem., 27: 63 (1976).

25. Turner, G. M., Oakley, C. M., and Dixon, H. G.: Management of pregnancy complicated by hypertrophic obstructive cardiomyopathy. Brit. Med. J., 4: 281 (1968).

26. Widdowson, E. M., and McCance, R. A.: A review: New thoughts on growth. Pediat. Res., 9: 154 (1975).

27. Wilson, J. T., Atwood, G. F., and Shand, D. G.: Disposition of propoxyphene and propranolol in children. Clin. Pharm. Ther., 19: 264 (1976).

28. Winick, M.: Cellular changes during placental and fetal growth. Amer. J. Obstet. Gynecol., 109: 166 (1971).

29. dl-Propranolol was a generous gift of Abic Ltd, Ramat-Gan, Israel.

30. Professor Atsmon is an Established Investigator of the Chief Scientist's Bureau, Ministry of Health, Israel.

31. Prof. Atsmon is presently on sabbatical at The National Institutes of Health Bldg. 10, Room 4N102, 9000 Rockville Pike, Bethesda, MD 20014.

32. Our thanks are due to Ms. J. Greenblat for her excellent technical assistance and to Dr. M. van Ham for his help in determining successful impregnation of the rats.

33. Requests for reprints should be addressed to: N. Schoenfeld, M.Sc., Laboratory of Biochemical Pharmacology, Beilinson Medical Center, Petah Tiqva (Israel).

34. Received for publication July 11, 1977

35. Accepted for publication October 18, 1977 